\title{
The Safety of Physics Science Activities in a High School Physics Classroom
}

\author{
Jennifer Bolla1, Retha Meier², Elizabeth Meyr² \\ ${ }^{1}$ Hazelwood East High School, St. Louis, MO, USA \\ ${ }^{2}$ Saint Louis University, St. Louis, MO, USA \\ Email: scuba31@mac.com
}

Received 27 July 2016; accepted 27 August 2016; published 30 August 2016

Copyright (C) 2016 by authors and Scientific Research Publishing Inc.

This work is licensed under the Creative Commons Attribution International License (CC BY). http://creativecommons.org/licenses/by/4.0/

(c) (i) Open Access

\begin{abstract}
High school physics teachers often turn to various resources, including the Internet, as they search for engaging physics activities for their students. An important question, especially for new physics teachers, concerns the safety of these activities. Have safety issues been adequately addressed within these activities? The purpose of this article is to emphasize potential safety issues involving high school physics projects as well as to provide a checklist for physics teachers to use as they evaluate activities. If the activity is deemed to contain safety issues, physics teachers are encouraged to attempt to modify the activity to make it safe. If the activity cannot be modified for safety purposes, then it is recommended that the physics teacher search for a different activity. The intention of this article is to provide high school physics teachers with safety information that can be used in preparing safe, inquiry-based, hands-on, engaging and topic-appropriate physics activities for their students.
\end{abstract}

Keywords

Activities, Checklist, Inquiry, Physics, Safety

\section{Introduction}

High school physics teachers are expected to provide safe, hands-on, inquiry-based activities for their students. These activities offer students the opportunity to apply and expand theoretical knowledge obtained from direct instruction and student-centered discussions. In addition, students develop knowledge and practices in designing, investigating, evaluating, and developing solutions and explanations to problems, as encouraged by the National Research Council [1]. High school physics teachers working within the public school system follow a district created curriculum based on either/both state and national standards as they develop their lesson plans and activ- 
ities.

Physics teachers are encouraged to use inquiry-based activities. According to the National Research Council ([1], pp. 42-43) "The actual doing of science or engineering can also pique students' curiosity, capture their interest, and motivate their continued study; the insights thus gained help them recognize that the work of scientists and engineers is a creative endeavor-one that has deeply affected the world they live in.” These activities begin with curriculum-based student-friendly learning targets created by the teacher. Students then develop or follow an investigation to answer questions previously generated. Following the investigation, students reflect upon their data and finally share their findings.

Because of the shortage of highly qualified certificated physics teachers, districts may hire individuals with temporary certification working toward full certification to teach physics or individuals qualified under unified science certification. Individuals who are not as highly qualified as fully certificated physics teachers may not be aware of safety concerns associated with physics activities. When considering which activities will be implemented within the classroom, physics teachers must ask themselves certain pertinent questions: 1) Does the lesson plan include safety precautions? 2) If yes, are the safety precautions appropriate? 3) What should the teacher do if the activity does not contain safety precautions? 4) How can a physics teacher determine if the activity is safe to implement? In order to assist these inexperienced physics teachers to address these questions, we have prepared a Safety Evaluation Checklist for Physics Teachers [2].

An activity safety checklist was developed to help physics teachers decide whether an activity is safe to use in their classroom. As shown in Table 1, the checklist is presented in categories that are frequently used in basic physics curriculums. The categories include the following: General Laboratory Safety, Motion (Kinematics), Momentum, Angular Momentum, Forces, Energy, Electricity, Magnetism and Electromagnetism, Simple Harmonic Motion, Waves, Optics, Buoyancy, Nuclear, Robotics, Field Trips, and Sensitivity to Student Feelings. This checklist provides the teacher with a quick reference for general safety measures as well as guidelines for specific physics categories. As teachers retrieve activities from various resources, they are encouraged to use the Safety Evaluation Checklist for Physics Teachers to determine if the activity addresses necessary safety concerns. Teachers can provide safe activities for their students to explore physical science inquiry-based investigations by following the safety procedures described in this article.

\section{General Laboratory Safety}

Students are to follow the general laboratory safety guidelines as provided by the physics teacher. Because moving parts can present a hazard, students are to avoid wearing baggy clothing, avoid wearing big, bulky jewelry, tie back long hair, avoid bringing unnecessary materials to the laboratory, e.g., cell phones, book bags, purses, and remove all ear phones/ear buds in the laboratory area [2]. Students are to wear closed-toed shoes. All physics activities are to be supervised by an adult certified to teach physics.

\section{Motion}

When students study motion, they observe how an object changes its position in space over a period of time. Included under the umbrella of motion are physics concepts of distance, time, speed, acceleration, velocity, and displacement. Frequently, meter sticks and stopwatches are used in motion activities to measure the speed of such objects as marbles or small toy cars. In the bowling ball pendulum activity, a stainless steel wire suspends a bowling ball from the ceiling. A student holds the bowling ball snugly against their nose and releases the ball. Upon returning, the ball is supposed to closely approach the student. We suggest modifying this activity because of the potential for causing harm. A model scale pendulum can be constructed using string, a rubber ball, and an action figure to demonstrate this activity.

Ramps are used in activities involving motion. An object is rolled on the ramp to predict horizontal distance from a known height. If ramps are elevated above floor level and the object is going to be projected onto the floor, caution must be used to avoid having the object hit a person.

Projectiles are often used to demonstrate the effects of motion. Foam darts provide safe forms of projectiles. However, metal darts, steel ball bearings, metal washers, and marbles pose specific hazards. It is proposed that these projectiles be used either in a closed environment or make a substitution for a safer form of projectile. Approved eye protection must be worn. 
Table 1. Safety evaluation checklist for physics teachers.

Does This Activity Include Any of The Following?

Category: General Laboratory Safety

Unsupervised science activities

Category: Motion

Bowling balls

Ramps

Projectiles

Meter sticks

Category: Momentum

Medicine balls

Carts

Category: Angular Momentum

Bicycle wheels

Category: Forces

Skateboards

Rockets

Category: Energy

Half balls (poppers)

Meter sticks

Category: Electricity

Batteries

Power supplies

Van der Graaff

Category: Magnetism and Electromagnetism

Magnets

Copper wires

Category: Simple Harmonic Motion

Pendulums

Pendulum bobs

Springs

Weights

Category: Waves

Slinkys

Candles

Resonance tubes

Tuning forks

Category: Optics

Magnifying glasses

Mirrors

Lenses

Prisms

Lasers

Category: Buoyancy

Glass containers

Rocks

Metal weights

Category: Nuclear

Radioactive substances

Category: Robotics

Robots

Category: Field Trips

Amusement parks

Bowling alleys

Nuclear power plants 


\author{
Continued \\ Category: Sensitivity to Student Feelings \\ Isolating activities \\ Humiliating activities \\ Derogatory remarks
}

Disclaimer: additional safety issues may exist. The intention of the authors of this article is not to identify every safety issue but rather to provide a general guideline for high school physics teachers to follow in safely selecting physics activities to implement in their classrooms.

Meter sticks are used to measure distance objects travel in motion activities. During these activities, students often sword fight using the meter sticks or twirl them like batons. It is therefore important for the physics teacher to inform students to use the meter sticks as intended.

\title{
4. Momentum
}

A moving object has momentum. Students examine the mass and velocity of a specified moving object to calculate its momentum. Common activities used by high school physics teachers to demonstrate momentum include bouncing balls on a variety of surfaces and the traditional egg drop inquiry. One activity identified on the Internet with safety concerns asks students to hit a wall with their fists. The next step is to place a pillow on the wall and then hit the pillow. This activity is not recommended because of the potential physical harm of hitting a wall with their hands.

\section{Angular Momentum}

Since angular momentum is a vector quantity, magnitude and direction specifications are necessary to describe it. Students in high school physics laboratories often use a bicycle wheel to explore angular momentum. One activity retrieved from the Internet suggests three ways of studying the bicycle wheel gyroscope. The rotating bicycle wheel gyroscope can be suspended from the ceiling, hand-held while standing, or hand-held while sitting on a rotating stool. Safety suggestions for this activity include making sure students tie back long hair and have no loose fitting clothing, dangly jewelry, or lanyards. If this activity is going to be used in an advanced placement physics class, we recommend using it as a demonstration and purchasing the bicycle wheel specialized for this project through a scientific company.

\section{Forces}

Students delve into Newton's Laws of Motion when they examine the effects of force upon an object and the object's subsequent acceleration. Many interesting and engaging resources are available to demonstrate the concept of force including launching ping pong balls, and observing mouse-trap cars in collisions. Skateboards and rocketry present concerns for safety. If a real skateboard is used in an activity, students will want to get on the skateboard and ride it. Therefore, we propose substituting toy skateboards for real ones and demonstrating the same physical principles using the miniature versions. An alternative solution is to have students sit on the skateboards instead of standing or they can sit on carts instead of using skateboards. If rocketry is chosen as a specific project, we recommend substituting the balloon rocket activity for an actual model rocket project. The same scientific principles can be demonstrated with the balloon rocket activity with fewer safety concerns. In this activity, an inflated long balloon is taped to a tube or straw through which a string has been strung. The safety concern with this activity is to use non-latex balloons in case someone has a latex allergy.

\section{Category: Energy}

When students explore the work necessary to cause an object at rest to accelerate and achieve a certain velocity, they learn about kinetic energy. Differences between potential energy and kinetic energy are often demonstrated in activities using foam darts, rubber bands, use of marbles on inclined planes, as well as swinging pendulums. Riding a roller coaster also nicely demonstrates this concept. An energy activity retrieved from the Internet is called the Dropper Popper activity. In this activity students turn half balls called poppers inside out and then drop them onto a hard surface. As stored energy is release, the popper pops higher than the point from which it was originally released. The main safety concern for this activity is the possibility for eye damage. Therefore it 
is important for students to wear appropriate eye protection. Meter sticks pose safety concerns as previously covered.

\section{Electricity}

Electricity can be generated as electrons move through a conductive substance. To learn about electricity students often build simple electric circuits using copper wire, a light source, and a battery. Safety precautions include being careful with the copper wire since it can be very sharp and puncture the skin and result in bleeding.

Batteries also present certain safety concerns. To reduce the probability of corrosion, remove batteries from objects when not in use, such as flashlights, cameras, and digital thermometers, and store the batteries in a clean, dry storage unit. Students are to avoid touching their tongues to the battery terminals. In addition, in situations where battery corrosion occurs, care should be taken in handling the damaged batteries and disposing of them. Batteries, depending upon the type, contain heavy metals such as lead and cadmium that can be harmful to both humans and to the environment. Lead-acid batteries contain lead sulfate and can release lead and sulfuric acid. Use of lead-acid batteries in the physics laboratory is not recommended. Nickel-cadmium batteries, common rechargeable batteries, contain the heavy metals cadmium and nickel. Cadmium can be absorbed through the skin. Lithium ion batteries, also rechargeable, are produced as lithium cobalt oxide, lithium iron phosphate, lithium ion manganese oxide, and lithium nickel manganese cobalt oxide. Lithium batteries are pressurized and contain a flammable electrolyte. Button batteries are small and pose a health risk when ingested. Since they can block the esophagus and cause internal chemical burns, it is suggested that students are reminded to avoid ingesting batteries, especially on a dare. Double A batteries (AA), dry cells, contain zinc-carbon and are general purpose batteries that deliver $1.5 \mathrm{~V}$. Alkaline batteries also deliver $1.5 \mathrm{~V}$ and when ruptured can result in irritations to skin, eyes, and respiratory system. We suggest wearing approved gloves when touching damaged batteries. Corroded and dead batteries are to be disposed of properly by dropping them into a battery-recycling center.

Power supplies are commonly used in the physics laboratory as a source of electricity. The main safety concerns with power supplies are to place them far away from a water source and check the wires on a regular basis for damage.

Van der Graaff devices are used primarily in the static electricity section as a demonstration. Students place their hands on the device for a hair-raising experience. To ensure safety, students must stand on a non-conducting surface such as wood or Styrofoam. Any student with any type of heart condition should avoid contact with the Van der Graaff device. It is important to keep electronic devices away from the Van der Graaff machine. Also, make sure that the Van der Graaff machine is discharged completely after it is turned off.

\section{Magnetism and Electromagnetism}

Magnets are frequently used in high school physics activities to demonstrate the relationship between magnetism and electricity. It is important to keep magnets away from computers since data storage within the computer may be damaged. Students examine magnetic fields, eddy currents, and electromagnetism as they explore the properties of magnets. When working with copper wire in building an electromagnetic coil, care must be taken in cutting and wrapping the coil to avoid puncture wounds. One physics activity retrieved from the Internet that presents safety concerns asks students to place a motor wrapped in plastic in their mouth and bite down on the motor for the purpose of hearing radio music. An electric radio is turned on and tuned in to a radio station. After inserting the phone plug into the headphone terminal, alligator clips are attached to the cable and connected to the motor's terminals. The plastic is supposed to serve as a sanitary barrier between students. Saliva contacting the plastic wrap creates a potential biohazard. Even if the saliva-contaminated plastic wrap is changed between students, microorganisms can contaminate the motor as well as surfaces and objects touched by students. In addition, placing an electrical device in a person's mouth is not recommended. Our suggestion is to avoid doing this activity and find a replacement.

\section{Simple Harmonic Motion}

Simple harmonic motion involves a repetitive motion where the restoring force is restored back proportionally to its original position. For example, the force that is required for a pendulum to swing to one side is equal to the force that is required for the pendulum to return to its original starting position. Safety concerns include students 
swinging the pendulum too hard and/or too far. When this happens, students can be struck with the moving pendulum bob. In addition, the bob can become unattached, becoming a flying projectile, and strike a person.

Hooke's Law involves progressively adding weights to a spring. Upon removal of the weights, the spring returns to its original position. Safety concerns for using Hooke's Law include dropping weights onto a person's foot as well as students placing their fingers between the spring coils.

\section{Waves}

A wave is a disturbance within a medium that creates an oscillation and energy is transferred through that medium. Since waves occur in light, air, and water, various resources are available to demonstrate waves including metal Slinkys, resonators, and spectroscopes. When a large, metal Slinky is used to demonstrate waves and wave interference patterns, students may become injured if the Slinky is stretched and one person releases their end of the Slinky. In addition, when a Slinky and spring are connected, if they are not well connected and they subsequently become unconnected during use, both the spring and the Slinky can retract and cause physical harm. The same can happen when using a rope in place of the spring.

One activity retrieved from the Internet used to demonstrate the concept of diffraction presents safety concerns. Students are instructed to light a candle, stretch a hair tight, and hold it about 2.5 centimeters from the eyes. The hair is aligned between the eye and the candle flame and the student is supposed to observe diffraction of light by the hair. Students are further instructed to replace the hair with a feather or piece of cloth. For fire safety concerns, we recommend replacing the candle with a non-Maglite flashlight or a small electrical circuit light bulb.

Resonance tubes are often used to find the speed of sound in air. A resonance tube is a hollow glass tube open at both ends. A resonance tube is inserted into a graduated cylinder filled 2/3 with water. A tuning fork is held over the open end of the resonance tube. While listening for the loudest sound, the resonance tube is moved up and down at the same time while moving the tuning fork up and down. Measurements are recorded and calculated to find the speed of sound. The main safety concern is to avoid striking the tuning fork into the glass resonance tube and/or graduated cylinder. A plastic graduated cylinder can be substituted for glass. A pre-laboratory demonstration emphasizes how to use caution while manipulating the tuning fork and resonance tube.

\section{Optics}

High school physics students learn about the properties and behavior of light that usually includes visible, ultraviolet, and infrared light in the section on optics. Resources commonly include mirrors, lenses, prisms, spectroscopes, magnifying glasses, and lasers. It is crucial to avoid using mirrors, lenses, and magnifying glasses in direct sunlight. Energy from the sun can damage the eyes. One activity retrieved from the Internet instructed students to burn paper, leaves, and wood using a magnifying glass and direct sunlight. This activity is not safe and it is therefore recommended to avoid burning objects using magnifying glasses and direct sunlight.

Types 1, 2, and 3R lasers are recommended for use in high school physics classes. Students are to avoid contact, avoid focusing laser beams directly into the eyes, and are also to avoid viewing the beam through a microscope, binoculars, telescopes or other optical equipment. When using approved laser beams in physics learning activities, it is important to prevent accidental exposure to the laser beam by aiming the laser beam in a safe direction. If reflective surfaces are used in the activity, they are to be arranged properly ensuring that the reflected beam travels in an intended, safe direction.

\section{Buoyancy}

High school students explore the tendency of objects to float in water, air, and other fluid mediums. Objects made from different materials in varying shapes are often dropped into containers of water to investigate Archimede's Principle. If a glass container is used, such as a beaker or fish tank, avoid using objects that can potentially break the glass, such as rocks and metal weights.

\section{Nuclear Energy}

Radioactive substances are difficult to obtain, store, and dispose of properly. Therefore, when students study nuclear reactions and the release nuclear energy, nuclear fission, radioactive decay, and nuclear fusion, high 
school physics teachers often use simulations, computer software programs, and virtual tours. If nuclear materials are present in the physics storage facility, our recommendation is to immediately contact administrators and request proper disposal. Field trips to nuclear power plants are often included in the physics curriculum (see category on field trips below).

\section{Robotics}

The integration of mechanical, electrical, and electronic engineering along with computer science provides students opportunities to design, build, operate, and apply knowledge and skills to make a machine. Robots are serving increasingly numerous roles in domestic, industry, military, and medical aspects of our society. Since this is a rapidly growing field and has been embraced by Science, Technology, Engineering, Art + Design, and Math (STEAM), middle and high schools are including after school and summer programs devoted to the field of robotics.

Two main types of methods for creating robots exist in high schools. One method uses pieces of metal and the robots are generally crafted in the shop room. Since serious bodily harm can result from shop accidents, this method is not recommended for constructing robots, especially for young people lacking experience working with pieces of sharp metal and unfamiliar mechanical equipment.

The second method uses kits containing directions for assembling a robot unit. Safety procedures are often lacking from these kits as well as appropriate age recommendations. If the robot has moving parts, such as fans, assembly manuals need to provide proper warnings. Protective safety gear, such as eye goggles, aprons, and gloves, also need to be addressed. Sharp objects are to be handled with great care and stored in sturdy containers with secure closures. These containers should never be stored above eye level. In addition, soldering poses two hazards. First fumes can be released during the soldering process so caution should be taken not to inhale these fumes. Second, the soldering iron is hot, as well as the heated metal. Therefore, much care must be taken to avoid burns. Close adult supervision is required for assembling robot kits.

\section{Field Trips}

Field trips allow students to observe the practical application of physics concepts. Popular field trips include amusement parks, bowling alleys, and nuclear power plants. While planning for a field trip, teachers are advised to visit the site to evaluate site safety and follow district guidelines for providing students with field experiences [3].

Pre-field trip considerations: Prior to taking students on any field trip permission must be obtained from parents and administrators. Arrangements for chaperones and lunches are to be made well in advance of the excursion. The teacher is responsible for checking for any student medical problems and to be prepared to address any medical situation that might arise.

Amusement parks offer students the opportunity to both study and experience a vast number of physics principles, including force, gravity, motion, and acceleration. Considerations include student apprehension to ride certain rides, motion sickness, and remaining with assigned groups. Guidelines provided prior to the field trip are to address these concerns. Students who have apprehension should not be forced to experience rides. Other assignments can be provided and students must know that this is perfectly acceptable. For those who experience motion sickness, responsible adults are to know the location of first aid stations and make sure that ill students receive proper medical attention. Students will also be reminded to remain with their assigned groups.

Bowling alleys provide a unique insight into physics concepts such as force, collision, and trajectories. Concerns for this outing include choosing the correct bowling ball size to avoid blisters, wearing socks in rented shoes (or bringing their own personal pair of bowling shoes), and remaining with the assigned groups. These concerns can be addressed through pre-field trip student advising.

Nuclear power plants allow students to observe firsthand how people capture and store nuclear energy. One main concern for this field trip is exposure to nuclear radiation. Students must be informed before the trip to avoid touching anything within the nuclear power plant, especially the water.

\section{Sensitivity to Student Feelings}

All teachers influence their students' behaviors and attitudes by serving as role models. The teacher's actions 
often send a clear message to the entire class. Therefore, it is important for high school physics teachers to be careful how they act and what they say. Teachers must avoid isolating, humiliating, and making derogatory comments to students. For example, in one high school physics activity retrieved from the Internet, the fellow classmates choose a boisterous class member that is thrown out of a virtual airplane. For some reason, the teacher draws a picture of the student falling from the virtual aircraft and colliding with the earth below. The teacher provides the height and speed of the airplane from which the students calculate how long it will take before the student hits the ground. The teacher actually asks the class how long the falling student screams before splattering on the ground below. This scenario presents an unnecessary graphic imagery that could potentially cause emotional harm to class members.

High school physics teachers must encourage all students to learn physics, regardless of their gender, race, culture, or ethnicity. Teachers should also be aware of and sensitive to students who are homeless, sexually harassed/abused, who are bullied, suicidal, and who may have physical and/or mental illnesses. Equity in education must occur in every classroom. It is important for the high school physics teacher to encourage students to work collaboratively and build trust and respect for one another.

\section{Legal Requirements}

Teachers have duties of care, instruction, supervision, and maintenance to ensure the safety, education, and wellbeing of their students [2] [4]. It is important for teachers to provide a safe environment for all students to learn. Students are to be supervised during all science activities and all projects are to be completed within the classroom/laboratory. Negligence may result in personal harm and lead to litigation against the teacher as well as the school district.

Equipment used in a physics classroom needs to be inventoried and inspected on a regular basis for imperfections and/or wear and tear. For example, electrical equipment must be examined for frayed cords and no exposed wires. Also, it is important for glassware to be in good condition so look for the presence of any chips or hairline fractures. It is recommended for teachers to make school administrators aware of any safety issues including class size violations, laboratory workspace, problems with equipment, and other related safety issues [3].

It is especially important for students to follow safety guidelines [2] [3] to ensure the safety of all students in the physics classroom and laboratory. Physics teachers should send safety acknowledgment forms (safety contracts) to parents/guardians to make them aware of best practices for physics instructional safety and file them according to state/district policy [5]. Specific safety guidelines are reviewed before every laboratory/activity. In addition, physics teachers often give a safety examination to all of their students after reviewing the general physics safety guidelines. This includes knowing emergency procedures and the location of specific safety equipment such as the fire blanket and fire extinguisher. It is suggested that teachers display safety posters and guidelines on classroom/laboratory walls and refer to those posters/guidelines when needed. NSTA recommends safety-training programs for science teachers [3]. This safety training covers their legal duty of care to students, addresses district and state safety regulations, and includes strategies for providing necessary accommodations for students with special needs [3].

\section{Conclusion}

High school physics teachers are expected to present engaging, safe, hands-on experiences for their students. Many teachers will retrieve physics activities from the Internet to use in their laboratories. How can a teacher know if an activity is safe to use in their classroom? The Safety Evaluation Checklist for Physics Teachers offers a reference for teachers to use to check for possible safety concerns. For example, a conservation of momentum activity was retrieved from the Internet. In this activity, two students are instructed to throw a large, heavy "medicine" ball to each other while sitting on separate carts facing one another. On-line instructions fail to include safety guidelines regarding how to throw the ball, the proper mass of the ball, how much force should be used to throw the ball, the distance apart the students are when the activity begins, no back support for students, and no face protection. When a physics teacher uses The Safety Evaluation Checklist for Physics Teachers, the boxes are checked for medicine ball and cart. The check marks indicate possible safety concerns. This activity is not safe in the way it is presented Online but can be modified to safely use in a physics laboratory. Modifications include using carts with back support, using a medicine ball appropriate for student size and weight, having students wear face protection, and beginning the activity by demonstrating how to throw and catch the medicine 
ball. In conclusion, if an activity is determined to be unsafe to use in the classroom, the high school physics teacher can modify the activity to make it safe. If the activity cannot be modified to ensure safety, then a different, safe activity should be substituted [2] [3].

\section{Acknowledgements}

We wish to acknowledge all the great science teachers we have taken classes from in the past who emphasized science safety.

\section{Author Contributions}

All three authors worked together as a team to produce this document.

\section{Conflict of Interest}

No conflict of interest exists in the writing of this document.

\section{References}

[1] National Research Council (2012) A Framework for K-12 Science Education: Practices, Crosscutting Concepts, and Core Ideas. Committee on a Conceptual Framework for New K-12 Science Education Standards. Board on Science Education, Division of Behavioral and Social Sciences and Education, The National Academies Press, Washington DC.

[2] Meier, R., Murdick N.L. and Lytle, C. (2014) The Safety of Science Activities in an Inclusive Elementary Classroom. Open Journal of Social Sciences, 2, 278-288. http://www.scirp.org/journals/jsshttp://dx.doi.org/10.4236/jss.2014.29046 http://dx.doi.org/10.4236/jss.2014.29046

[3] National Science Teachers Association (NSTA) (2015) NSTA Position Statement: Safety and School Science Instruction. www.nsta.org/about/positions/safety.aspx

[4] Prosser, W.L., Keeton, W.P., Dobbs, D.B., Keeton, R.E. and Owen, D.G. (1984) In: Keeton, W.P., Ed., Prosser and Keeton on Torts, 5th Edition, West Group, St. Paul.

[5] National Science Teachers Association (NSTA) (2013) Safety in the Science Classroom, Laboratory, or Field Sites. https://www.nsta.org/docs/SafetyInThe Science ClassroomLabAndField.pdf

\section{Submit or recommend next manuscript to SCIRP and we will provide best service for you:}

Accepting pre-submission inquiries through Email, Facebook, LinkedIn, Twitter, etc.

A wide selection of journals (inclusive of 9 subjects, more than 200 journals)

Providing 24-hour high-quality service

User-friendly online submission system

Fair and swift peer-review system

Efficient typesetting and proofreading procedure

Display of the result of downloads and visits, as well as the number of cited articles

Maximum dissemination of your research work

Submit your manuscript at: http://papersubmission.scirp.org/ 